\title{
ON THE INTERPRETATION OF PULSE-TRACINGS.
}

BY ARTHUR R. CUSHNY.

(From the Pharmacological Laboratory of the University of Michigan.)

Plates XVI and XVII.

The physiology of the mammalian heart has advanced with such rapid strides of late years, that clinical observers have apparently had difficulty in keeping pace with it, and but little attempt has been made to adapt the theories of the experimental investigators to the observations made on the diseased heart. It is true that the explanation of the undulations on the pulse-tracing and of their modifications in pathological conditions has engaged the attention of a considerable number of observers, but until quite recently the divergences of the cardiac rhythm from the normal seem to have aroused little interest, and no attempt was made to explain the origin of the irregularities of the pulse. In the following pages I have endeavored to fill in one hiatus existing between clinical observation and physiological experiment.

The ventricular systole which causes the radial pulsation is, in the normal heart, induced by an impulse descending from the auricle through communicating fibres which are generally held to be formed of muscular tissue; the normal ventricle never contracts unless it is excited by the arrival of such an impulse from above. It is obvious that an irregularity in the ventricle (and consequently in the pulsetracing) may arise (1) from the ventricle failing to respond normally to this impulse or from its contracting independently of it or (2) from the auricle failing to emit an impulse at the ordinary interval. Yet it is only of recent years that the work of Krehl and Romberg* has led to the general recognition that an irregularity of the pulse may be due to disorder of the higher parts of the heart, which determine the normal rhythm. Nor has the importance of the auricle as a factor in

*Arch. f. exp. Path. u. Pharm., 1892, xxx, p. 49. 
ventricular irregularity been appreciated apparently by pathologists as yet, for, with the exception of Radasewsky's* paper, I have been unable to find any accounts of examination of the auricle in cases of irregular pulse.

My attention was drawn to the subject by the results of a series of experiments performed some years ago along with Matthews and during the last year I have through the kindness of Dr. Dock and his staff had the opportunity of examining a considerable number of sphygmographic tracings taken in cases of irregularity of the pulse. I propose in the following pages to attempt to interpret these clinical observations in terms of our experimental results.

The object of our experiments, which were performed on dogs, was to ascertain the effects of a single stimulus applied to the heart. It is unnecessary to revert to most of our conclusions, which bear rather on physiological than on practical points, and which have been published elsewhere. $\uparrow$ Let it suffice to state that the movements of the auricle and ventricle were recorded separately by a system of levers, and that in a number of instances a sphygmographic tracing was taken simultaneously from the carotid artery. When a single electric shock was passed through the ventricle at any time except in the refractory period, it was followed by a premature contraction of that chamber (Fig. 1, p. 329). In many instances this contraction expelled sufficient blood to cause an undulation in the sphygmographic tracing, this undulation being lower than that caused by a normal pulse and occurring at a shorter interval than usual after the last ordinary elevation. But as a general rule the contraction of the ventricle (premature contraction) was too feeble to cause a pulsation of the artery. In Fig. 1, a premature systole $(c)$ of the ventricle was induced by an electric shock which reached that chamber at a point indicated by the crosslines $X$ in the ventricular tracing. It was succeeded by relaxation, and the ventricle then remained quiescent until it was aroused to activity $(d)$ by an impulse descending from the auricle. The auricular rhythm was unaffected by the irregularity of the ventricle. If the course of each impulse be followed from the auricle to the ventricle and finally to

* Ztschr. f. kl. Med., 1895, xxvii, p. 381.

$\dagger$ Journal of Physiology, xxi, p. 213. 
the pulse, it is found that $A$ is followed by $a$ and then by $a, B$ by $b$ and then by $b$. But $C$ beginning in the auricle has no effect on the ventricle, which it reaches during the premature systole $c, i$. e. during a refractory period. $D$ is followed by $d$, however, and later by $\underline{d}$ and the normal sequence is then reinstated. The interval between the normal pulsations $\underline{b}$ and $\underline{d}$ or between the ventricular systoles $b$ and $d$ is determined by that between the auricular contraction $B$ and $D$. And as the auricular rhythm is perfectly regular throughout, the interval $B-D$ is twice that of $B-C$ or twice $A-B$ or $D-E$. That

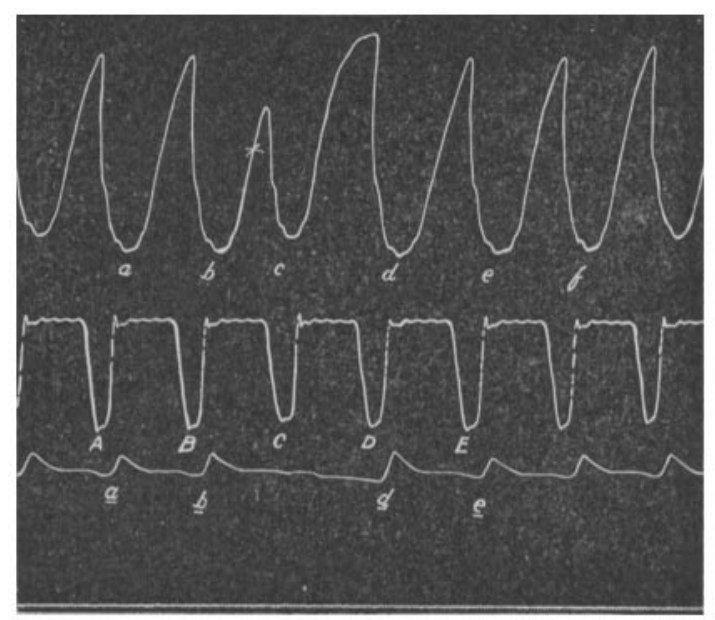

Fig. 1.

In Figs. 1 and 2 the upper tracing was drawn by the ventricle, the next by the auricle, the third by a sphygmograph (Frey's) attached to the carotid artery, and the fourth by a tuning-fork swinging 50 times per second. During systole the auricular and ventricular levers made a stroke downwards. During diastole they rose again. For further explanation see text.

is, the interval between the two normal pulsations of the artery, or the duration of the intermission, is equal to twice the usual interval between two pulsations (pulse-interval).

A little consideration will show that as long as the auricle is beating regularly, an intermission which is due to ventricular failure must always be equal to twice the ordinary interval. For example, had there been no premature contraction (c) in Fig. 1, but had the ven- 
tricle relaxed and remained quiescent until it was aroused by the impulse $D$, the length of the interval would have been the same. So that a general law may be formulated, that an intermission which is due to ventricular disorder and during which the auricle continues to contract regularly must always be equal in length to twice the ordinary pulse-interval.

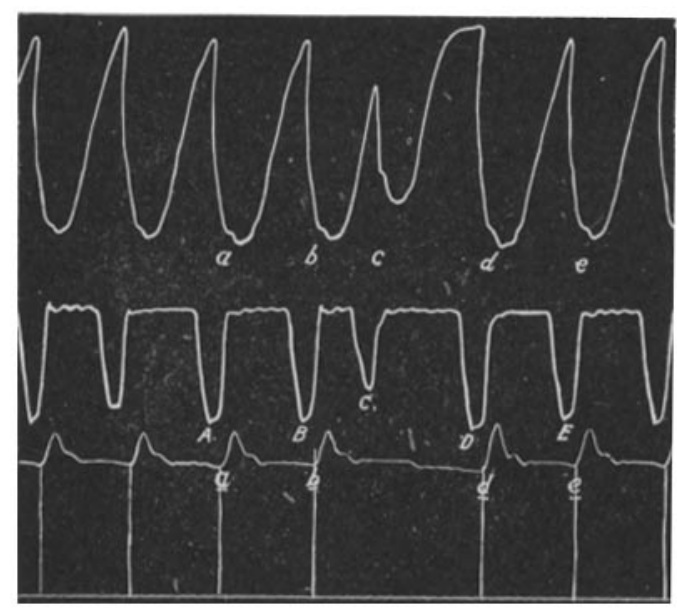

Fig. 2.

For explanation see Fig. 1 and the text.

When an electrical shock is passed through the auricle (Fig. 2), a premature systole is caused in that chamber exactly as in the ventricle, but it does not remain limited to the auricle but is transmitted to the ventricle, which contracts prematurely as if it had received a direct stimulus; a weak premature pulse is sometimes seen in the artery, but here again the blood expelled is generally too small in amount to cause any appreciable movement and the tracing displays a complete intermission. In Fig. 2, $A$ gives rise to $a$ and $a, B$ to $b$ and $\underline{b}$ and $C$ to $c$, which is not followed by a distinet movement in the artery. The next normal auricular systole, $D$, is followed by $d$ and $d$ and $E$ by $e$ and $\underline{e}$. The only difference from Fig. 1 apparent at first sight is the irregularity of the auricle, and as this is not visible in the sphygmographic tracing, it might be supposed that an irregularity of auricular 
origin is followed by the same changes in the pulse as one arising from ventricular disorder. When the sphygmographic tracing is subjected to exact measurement, however, a difference is observed in it; the intermission is shorter than twice the ordinary pulse-interval. For example, if the intervals $a-b, b-d$, and $d-e$ are measured, it will be found that $\underline{a}-\underline{b}$ and $\underline{d}-\underline{e}$ are each equal to $\frac{2}{\bar{b}} \frac{\gamma}{0}$ sec. If the intermission $\underline{b}-\underline{d}$ were twice the normal interval, it would last $\frac{54}{50}$ sec., but in reality it is only $\frac{4}{5} \mathrm{~g}$ sec. in duration. The explanation of this point is simple-the auricle itself gives rise to the rhythm of the heart. The impulse leading to the contraction $D$ is not derived from any higher rhythmical organ, but arises from the auricle itself. When the auricle has collected enough energy or irritability to cause a contraction, the systole follows, this chamber not waiting as the ventricle does for some impulse from without. The exact length of the intermission in these stimulation experiments varies with the point in the auricular cycle at which the electric shock was given, but it is unnecessary to enter on this here. The important fact is that in these experiments the intermission was always shorter than twice the ordinary pulse-interval. Consideration will show that here again a general rule may be formulated, that the intermissions due to auricular disorder are not necessarily equal in length to twice the ordinary pulse-interval. For example, the auricle may stand still for any interval of time and then resume its contractions. It is not necessary that it should contract at the exact time at which it would have done so normally, any more than it is necessary that if the breath be held for some time, the next inspiration will follow at any definite moment. When the probabilities of the case are considered, it will be seen that the chances of the auricle resuming its contractions at the end of a double pulse-interval are small. The irritability of this chamber increases very rapidly when it is quiescent and in most cases must reach the point at which a contraction is elicited sooner than after two intervals.

These considerations appear to be sufficient basis for the general statement, that intermissions of the pulse which are due to ventricular disorder must be equal in length to two normal intervals, while those 
that are of auricular origin may be of this length, but in the great majority of cases are not of this duration but shorter. Conversely, intermissions of the pulse which are equal to two ordinary intervals, are in all probability ventricular in origin; those which are shorter are certainly not ventricular and are therefore due to auricular derangement.

A few examples of the duration of the intermissions in the dog's pulse under stimulation of the ventricle and auricle may serve to elucidate this question (Table 1, p. 343). It may be stated that these do not by any means exhaust the numbers at my disposal, for $I$ have made a large series of experiments on the subject and have measured some hundreds of intermissions, all of which gave the same result without exception. I have selected some of the measurements of only two of these experiments, however, which are sufficient to give an idlea of the extent of the variation in the length of the intermissions. When the stimulus resulted in a premature arterial pulse, the intervals before and after it are enclosed in brackets, in order to allow of a comparison with those in which there was a complete intermission. In column $A$, the duration of the normal interval is given in hundredths of a second; in column $B$, the part of the heart stimulated; in column $C$, the duration of the intermission in hundredths of a second; in $D$, the extent by which this fell short of two complete intervals $(2 A-C)$; and in $E$, the fraction of a pulse-interval represented by this deficiency $\frac{D}{A}$. In the last column the averages of, and the extremes of, $E$ are given approximately.

In Table 1, it will be observed that when the intermission is due to ventricular stimulation, it is equal to a double interval, the greatest deviation from this amounting to only $\frac{1}{54}$ and $\frac{1}{4^{6}}$ of the normal pulse-intervals, numbers which may well be considered within the limits of error. When the stimulus was applied to the auricle, on the other hand, the resulting intermission was invariably shorter than a double pause, the deficiency varying from $\frac{1}{13}$ to $\frac{2}{5}$ of a normal pulse-interval according to the exact position of the auricle when the stimulus reached it. It may be added that the deficiency differs in 
different hearts, that in Experiment 2 being distinctly greater than in Experiment $1 ; i . e$, in the second experiment, the auricle seems to regain its irritability more rapidly than in the first, and this is probably to be correlated with the fact that the rhythm is faster in the second.

When one attempts to apply the principles deduced from these animal experiments to analysis of clinical sphygmographic tracings, one is met by the difficulty that in some of these the pulse is so irregular that no normal interval can be ascertained with certainty. These may be passed over at present and only thase tracings will be considered in which the rhythm is regular on the whole, but in which intermissions or -other irregularities appear at longer or shorter intervals. In these also there occur small differences in the pulse-interval, and even in some perfectly normal individuals a considerable variation has been shown to exist by von der Mühll.* These differences seldom amount to more than one or two hundredths of a second, however, so that they do not materially affect the results. In order to eliminate the error so far as possible, I have generally taken the average of three or four pulses preceding and following the irregularity and thus obtained an average interval, which was compared with that immediately preceding and immediately following the intermission. In this way certainty could be reached that the interval taken as a basis for the calculation really was that which would have occurred had no irregularity been present, or at any rate did not depart very far from this ideal interval.

The tracings were taken with Jaquet's sphygmochronograph, which is the only instrument available when such minute intervals as $\frac{1}{100}$ second have to be dealt with. In analysing the tracings I have used his curve-reader (Curvenanalysator), which was kindly put at my disposal by Professor Lombard. A number of tracings were taken in each case, and the irregularities were all carefully measured and compared, and an average taken of the extent to which they fell short of a double interval. Only in this way can any reliable results be attained, as not infrequently one individual intermission may appear to be of auricular origin, while when it is compared with the others of

*Deutsches Arch. f. klin. Med., 1892, xlix, p. 348. 
the series it is seen to be so nearly equal to two pulse-interrals that it falls into the group of ventricular intermissions.

In Table II (pp. 344-5), I have arranged a series of intermissions or irregularities (premature pulsations), which approach the type found to be due to ventricular stimulation in the dog; and in Table III (pp. 346-7) intermissions approximating those from stimulation of the dog's auricle. The columns correspond to those of Table I (p. 343) except that the second column is omitted.

In Table II, the average deviation from a double pulse-interval varies from zero up to $\frac{1}{20}$ of a pulse-interval. In regard to Case W, I had some doubt whether it should be placed in Table II or in Table III, and the number of tracings at my disposal was not sufficient to permit a certain interpretation. In Table III, the average intermission was $\frac{1}{5}-\frac{1}{3}$ of a pulse-interval shorter than two pulse-intervals.

When Tables II and III are compared with Table I, there is noted a very striking resemblance between the intermissions due to ventricular stimulation and Table II, and between those due to auricular stimulation and Table III. This resemblance at once suggests that the disorder in the hearts from which Table II was derived was ventricular, while the cases from which the tracings analysed in Table III were obtained, suffered from disease of the auricle. It may be added that the line of demarcation between the two sets of tracings is very sharply drawn. In Table II, the fractions in column $E$ are all so small that they may be regarded as lying within the limits of error, while those in Table III, column $E$, are so large that no such explanation is possible. There were no intermediate cases except W (Table II), and even in this tracing the intermissions are very different from those of Table III. It may be added that these were not selected tracings, but were those obtained from 14 of the first 16 cases of irregularity which came under my observation. In the remaining cases the tracing was so irregular that no definite pulse-interval could be recognized, and they have therefore been omitted from the tables. None of the intervals in these tracings were double the others in length, however, so that there can be no doubt that the irregularity was due to auricular derangement. In all of these cases, then, a care- 
ful examination enabled a diagnosis to be formed as to whether the irregularity was due to functional disorder of the auricle or of the ventricle.

The further question arises as to what is the nature of the intermission of the auricle or ventricle in these cases. The heart may fail to cause a pulse-wave, firstly, because the ventricle contains so little blood when it executes a premature contraction that the arterial pressure is not increased enough to move the sphygmograph, or, secondly, because the ventricle entirely fails to contract or contracts too weakly. A very important contribution to this subject has been made by Wenckebach* since I began my investigations; in fact this writer has anticipated many of the conclusions at which I had arrived independently. $\dagger$ He discusses almost exclusively the intermissions which are equal to two pulse-intervals and states that these are invariably due to premature idioventricular contractions. His grounds for this view are two-fold in nature: in the first place he was able in every case to make out by auscultation a double contraction sound in the beginning of the intermission, and in the second place a pulse-tracing which at one time shows a complete intermission very often shows immediately afterwards an intermission interrupted by a weak premature elevation. I have met this in most of my own cases, and there is no question that many, perhaps most, cases of ventricular intermission are due to this premature contraction (extrasystole, Wenckebach) so that they correspond in every feature with those obtained in my experiments on the dog, except that in man the ventricular stimulus arises spontaneously in the ventricle while in my experiments it was artificial. In a number of instances, however, I have observed an extrasystole in the dog without any electrical stimulus having been supplied, and in these cases the intermission was identical in every feature with that observed in the human pulse.

It may be questioned, however, whether this is the explanation in every case of ventricular intermission, as Wenckebach holds, for in one

*Ztschr. f. klin. Med., 1899, xxxvi, p. 181.

† Among other points he noted that in many cases the intermission fell short of two pulse-intervals, and ascribes these to auricular disorder, basing this explanation on our experimental results already referred to. 
of our patients the most careful stethoscopic examination failed to detect any systolic sound during the intermission. I am inclined to regard the intermission in this case as due to a complete failure of the ventricle to respond to the auricular impulse, or to the impulse having been blocked in the communicating fibres between the auricle and ventricle.

As regards the intermissions which are cansed by auricular derangement, the cause is unquestionably a premature auricular contraction in a certain number of instances. This is demonstrated by the appearance of a distinct undulation in the pulse-tracing in some cases (Plate XVI, Fig. 8), while in others a number of complete intermissions are interrupted by one which shows this premature pulsation. These intermissions are therefore analogous to those observed in the dog on stimulation of the auricle, for here also the fall of the pulselever is sometimes unbroken (complete intermission), at other times interrupted by a slight undulation. In the clinical sphygmographic tracings the premature systole of the auricle is of course caused by some intracardiac stimulus, and I have therefore sought for descriptions of auricular disease in the literature of the heart, but have as yet found only one paper, viz.: that by Radasewsky," in which the auricle was subjected to careful post-mortem examination with reference to this point. He states that of six hearts examined by him four presented more severe lesions in the auricle than in the ventricle and in these cases there was a history of marked irregularity of the pulse; in one in which the ventricle alone was diseased, and in another in which both auricle and ventricle were less extensively degenerated, no marked irregularity had been noted before death. In one of my cases in which the measurement of the pulse demonstrated clearly that the intermissions were of auricular origin (Table III, Case Sh), the autopsy showed an enormous dilatation of all the chambers; the auricular walls were thin and transparent and the muscular bundles formed a network separated by wide meshes composed of the serous membranes only.

Those cases in which the irregularity is due to an extrasystole arising in the auricle are indicative of some disorder in this chamber,

* Ztschr.f. klin. Med., 1895, xxvii, p. 381. 
which may prove to be of grave import, though my experience has been too limited to allow of any certain statement as to the value of this sign in prognosis. But every case of intermission in which the interval is shorter than two complete pulses does not necessarily indieate the presence of auricular disease. In fact this probably holds for only a small proportion of the cases in which it occurs; for these lapses are very often seen in perfectly healthy persons, and no line can be drawn separating them from the slight irregularities of the normal pulse. For example one of my tracings, taken from a healthy woman, shows a somewhat irregular rhythm, the pulse-interval ordinarily varying from 54 to 61 hundredths of a second, but occasionally an intermission of 90 to 100 hundredths of a second appears. These intermissions can be elicited with regularity by instructing the patient to take very deep inspirations, and are obviously not due to auricular disease but to excessive activity of the inhibitory centre. As is wellknown, this centre is peculiarly sensitive in some individuals, and in this case it is capable of arresting the heart completely for a short time. The whole heart is arrested and the intermission is therefore of the auricular type. Exactly the same phenomenon can be elicited in animals by stimulating the pneumogastric nerve in the neck for a fraction of a second, as may be seen by comparing the sphygmogram from a healthy woman (Plate XVII, Fig. 13) with that from a dog whose vagus was stimulated electrically (Plate XVII, Fig. 14).

This inhibitory intermission is liable to be confused with the true auricular intermission, and in fact I am inclined to regard the irregularity in the first case. in Table III as due, at any rate in some part, to inhibition. There are certain distinguishing features, however; in the first place the intermission is often followed by a second long interval, because the inhibition seldom lasts over only one beat; in the second place, the intermission is often, but not always, too short to arise from auricular irregularity. Thus the shortest intermission which I have observed in the dog's heart from stimulation lasted $1 \frac{3}{5}$ pulse-interval, but the inhibitory intermission may be only $1 \frac{1}{5}$ pulseinterval. In case of doubt the question could be determined by the pulse being rendered regular when the inhibitory terminations are 
paralyzed by atropine, for this drug is without effect on the true auricular intermissions. Dehio* has observed arythmia disappear under this treatment in a number of instances.

The occurrence of this false auricular intermission suggested the question whether in some cases ventricular intermissions might not be due to inhibition, for it is well known to physiologists that stimulation of the pneumogastric nerve retards the passage of impulses from the auricle to the ventricle, and renders the latter less susceptible to stimulation. It is thus conceivable that some of the ventricular intermissions might be due to the impulse from the auricle finding the passage to the ventricle blocked or the ventricle incapable of responding to it owing to powerful inhibition; but there seems to be no reason to suppose that this occurs, for the rhythm of the heart would be reduced to 20-30 per minute or less by inhibition powerful enough to block the communicating fibres or to prevent the ventricle entirely from responding to a stimulus. It is very probable that in many instances intermissions of different kinds may occur in the same pulsetracing. For example, both ventricle and auricle may contract prematurely at intervals, or an intermission due to a premature systole of the ventricle may alternate with one due to inhibition. I have not been able to identify such a mixed tracing with certainty among those hitherto examined, but in one or two of them in which the irregularities were mainly of the auricular type an occasional intermission approached so nearly to the double pulse-interval, that it aroused the suspicion that the ventricle also was involved.

I have stated that an excessively irregular pulse indicates auricular rather than ventricular derangement, but this requires some qualifications. For example, Fig. 10 (Plate XVII) was obtained from a patient in whom ventricular intermissions occurred frequently, but who never presented any signs of auricular disorder. Yet the pulse-intervals in Fig. 10 are $48,47,48,48,49,47,41,95,50,34,60,47,47,48$, which would seem at first sight to indicate disorder of the rhythmic area rather than of the ventricle. The explanation appears to be that several ventricular premature systoles occurred in succession, that $a, b$

* Deutsch. Arch. f. klin. Med., 1893, lii, p. 97. 
(a rudimentary beat), $c$ were all due to idioventricular contractions, while $d$ was due to an auricular impulse and $e$ was again idioventricular. Thus the intervals are $41+95+50=186=4 \times 47-2$; $i$. e., while the ventricle was beating $a, b$, and $c$, the auricle was contracting regularly three times but in a slightly different rhythm. The fourth auricular contraction was propagated to the ventricle. A premature idioventricular pulsation followed this and the sixth auricular beat again reached the ventricle and induced $f$. That the auricular rhythm was regular is shown by the sixth ventricular contraction oceurring at the exact point at which it would have fallen had there been no irregularity at all (i. e. $41+95+50+34+60=280=$ $6 \times 47-2$ ) for the slight difference of $\frac{2}{100}$ of a second can be neglected. In several other instances a similar apparent irregularity can be reduced to several idioventricular beats following each other, as has been demonstrated by Wenckebach. These repeated premature systoles certainly present difficulties in analysis, but in cases in which the tracings indicate uniformly ventricular intermissions, it is of interest to attempt their solution as instances of ventricular derangement only. If the other sphygmograms in this case had not invariably indicated a perfectly regular auricular rhythm, I should have hesitated to interpret this particular irregularity as ventricular.

This repetition of the ventricular extrasystole suggests the question as to whether in some cases the pulse-rhythm may not be entirely ventricular, the auricles beating at a different rate or perhaps being quiescent. It is generally recognized that the mammalian ventricle is capable of carrying on the circulation alone, and it is quite possible this may occur in disease. In this case the rhythm may be irregular also, and the intermissions are not necessarily equal to double pulseintervals although the ventricle alone is involved, as I showed with Matthews in our earlier article. This purely ventricular rhythm presupposes such grave disorder of the whole heart, however, that it can scarcely be regarded as of frequent occurrence, and though it would be impossible to diagnose it by the sphygmogram from the auricular irregularity, it need not be regarded as an alternative diagnosis in cases of short intermissions, until further evidence of its existence in man is adduced. 
In many instances the extrasystoles or the intermissions appear regularly in the tracing, whether these be of ventricular or of auricular origin. For example, Fig. 11 (Plate XVII) is a tracing in which every second contraction for some time is an idioventricular extrasystole; in Fig. 12 (Plate XVII) every third is an extrasystole of the ventricle; in Fig. 3 (Plate XVI) every fourth is a ventricular extrasystole, while in Fig. 9 (Plate XVII) every fourth is an auricular extrasystole. This rhythmical irregularity is difficult to explain, for it is generally believed that the irritability of the heart is exhausted at every systole, so that there cannot be a summation of residual energy until sufficient is accumulated to give rise to an extrasystole. A failure of the ventricle to contract at intervals is much more readily intelligible, for it is easily conceivable that the contractile or conducting substance is exhausted entirely after every 2 nd or 3 rd beat, and until it is restored no contraction can occur. In many instances, however (e.g. Fig. 11, Plate XVII), the irregularity is obviously due to an extrasystole and not to a failure to contract. It may be added that the same phenomenon is frequently seen in animals poisoned with digitalis or its allies or with barium salts, that is, with bodies which increase the irritability of the heart. The periodic appearance of the extrasystole may therefore be due to some alteration in the heart through which the irritability is not entirely annulled by the contraction, and the residue is summed up until it gives rise to a premature systole.

A few words may be added in regard to the extreme irregularity of the heart known clinically as delirium cordis. It is unnecessary to explain that in physiology this term is used to indicate fibrillary contractions of the heart, which arrest the circulation and prove immediately fatal. The clinical sphygmogram in these cases resembles exactly that obtained from dogs when the auricle is undergoing fibrillary contractions, which may be continued for a long time without proving fatal. I do not wish to assert that the clinical delirium cordis is identical with the physiological delirium auriculæ, but the resemblance is certainly striking. The fibrillary contraction of the auricle may be induced by stimulating it by means of rapid induction shocks, 
and possibly by other forms of stimulation. In some cases I have observed it in the dog before the heart was injured in any way, and in some of these cases it could be arrested and the pulse rendered perfectly regular by division of the vagi or by paralyzing their terminations by means of atropine. This connection between the inhibitory mechanism and fibrillary contractions was scarcely to be anticipated from what is known at present regarding inhibition, but is confirmed by the observation made by Matthews and by Cash that atropine prevents the irregularity and final delirium of the heart from aconitine. It would be of interest to ascertain the effect of atropine on clinical delirium cordis.

In conclusion, I have much pleasure in acknowledging my indebtedness to my colleague Dr. Dock for his kindness in putting his tracings at my disposal, and to Drs. Arneill and Boyce for the help they have afforded me in various ways, particularly in collecting tracings which bore on the subject of investigation.

\section{DESCRIPTION OF PLATES XVI AND XVII.}

Figs. 1-2 are inserted in the text and there explained (pp. 329, 330).

\section{Plate XVI.}

Figs. 3-13. Sphygmograms from human tracings. The pulse-intervals and intermissions are measured below in hundredths of a second.

Fig. 3. Every fourth pulse-beat is missed, and the intermission is practically exactly twice the normal interval, $i$. $e$. the ventricle alone is involved in the irregularity.

Figs. 4 and 5. Single intermissions each equal to two intervals.

Fig. 6. Single intermission shorter than two intervals $(2 \times 95=190)$ and therefore of auricular origin.

Fig. 7. Three intermissions each shorter than two intervals. In the first (lasting $\frac{115}{1} \frac{5}{6}$ ) and third (lasting $\frac{1}{1} \frac{1}{0} \frac{4}{0}$ seconds) there is evidence of a premature contraction early in the intermission, but this is absent in the second.

Fig. 8. The pulse is fairly regular at first, but, later, intermissions follow each other, each being shorter than two full intervals. In the first of these there is a distinct premature contraction, $\frac{40}{100}$ sec. after the last normal beat.

Plate XVII.

Fig. 9. Every fourth beat is missed, and each intermission is shorter than two full intervals; $i$. $e$. the irregularity is auricular in origin. Contrast Fig. 3.

Fig. 10. Irregularity in ventricular disease (see text, pp. 338, 339). 
Fig. 11. Ventricular premature systole occurring alternately with that derived from the auricle. This form of irregularity lasted for several minutes and then gave place to a regular pulse having an average interval of 64-67 hundredths of a second.

Fig. 12. Every third beat is missed, and the intermission is so nearly equal to two intervals that it may be regarded as due to ventricular disorder only.

Fig. 13. An intermission caused by excessive activity of the inhibitory apparatus and not to true cardiac disease. It simulates auricular intermission.

Fig. 14. An intermission caused in the dog's pulse by stimulation of the vagus nerve for $\frac{1}{2}$ sec. Compare Fig. 13 . 
THE JOURNAL OF EXPERIMENTAL MEDICINE. VOL. IV.
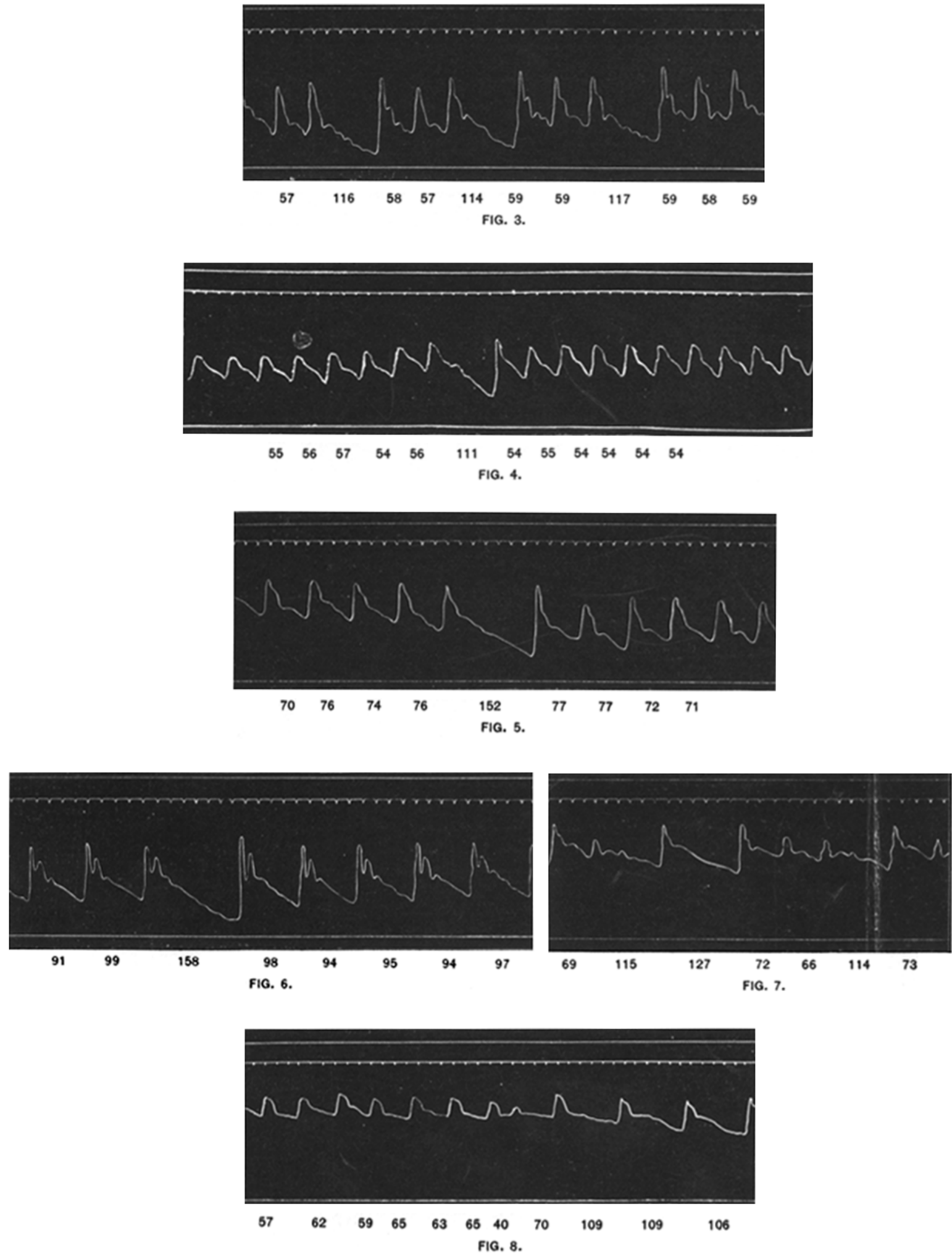
THE JOURNAL OF EXPERIMENTAL MEDICINE. VOL. IV.
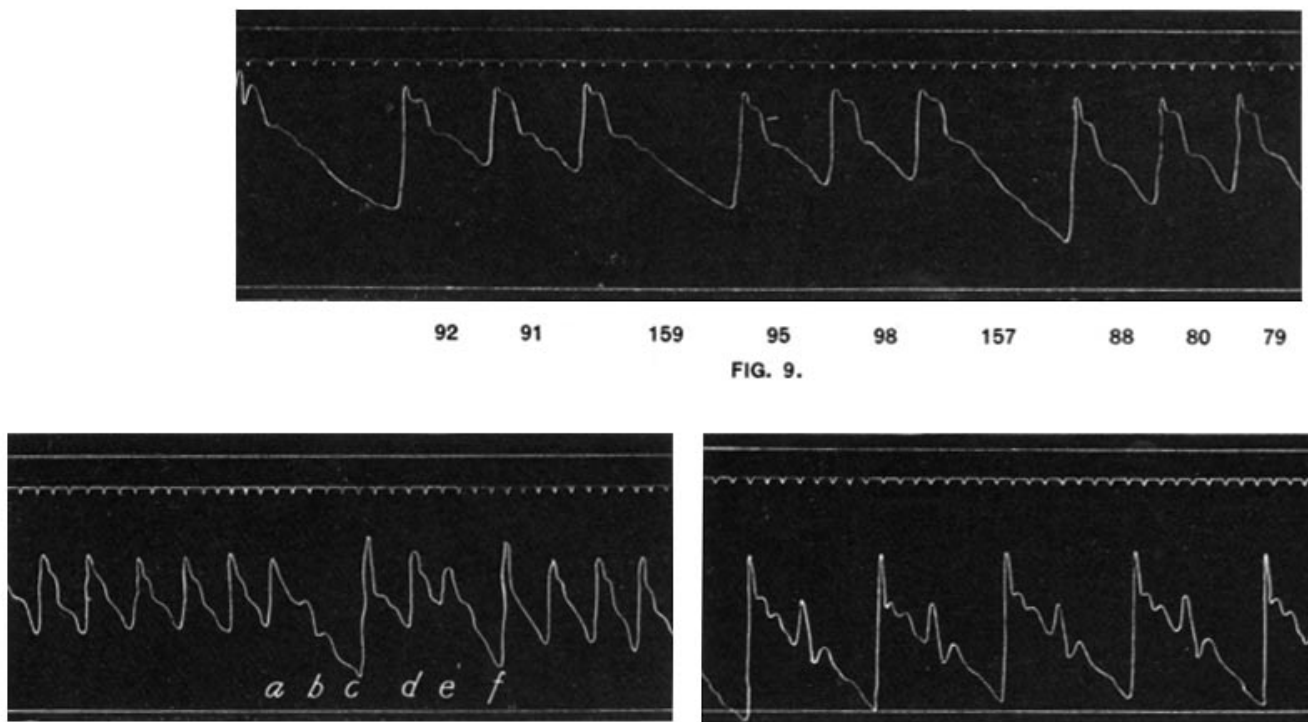

$\begin{array}{lllllllllllll}48 & 48 & 49 & 47 & 41 & 95 & 50 & 34 & 60 & 47 & 47 & 45 & 44\end{array}$ FIG. 10.
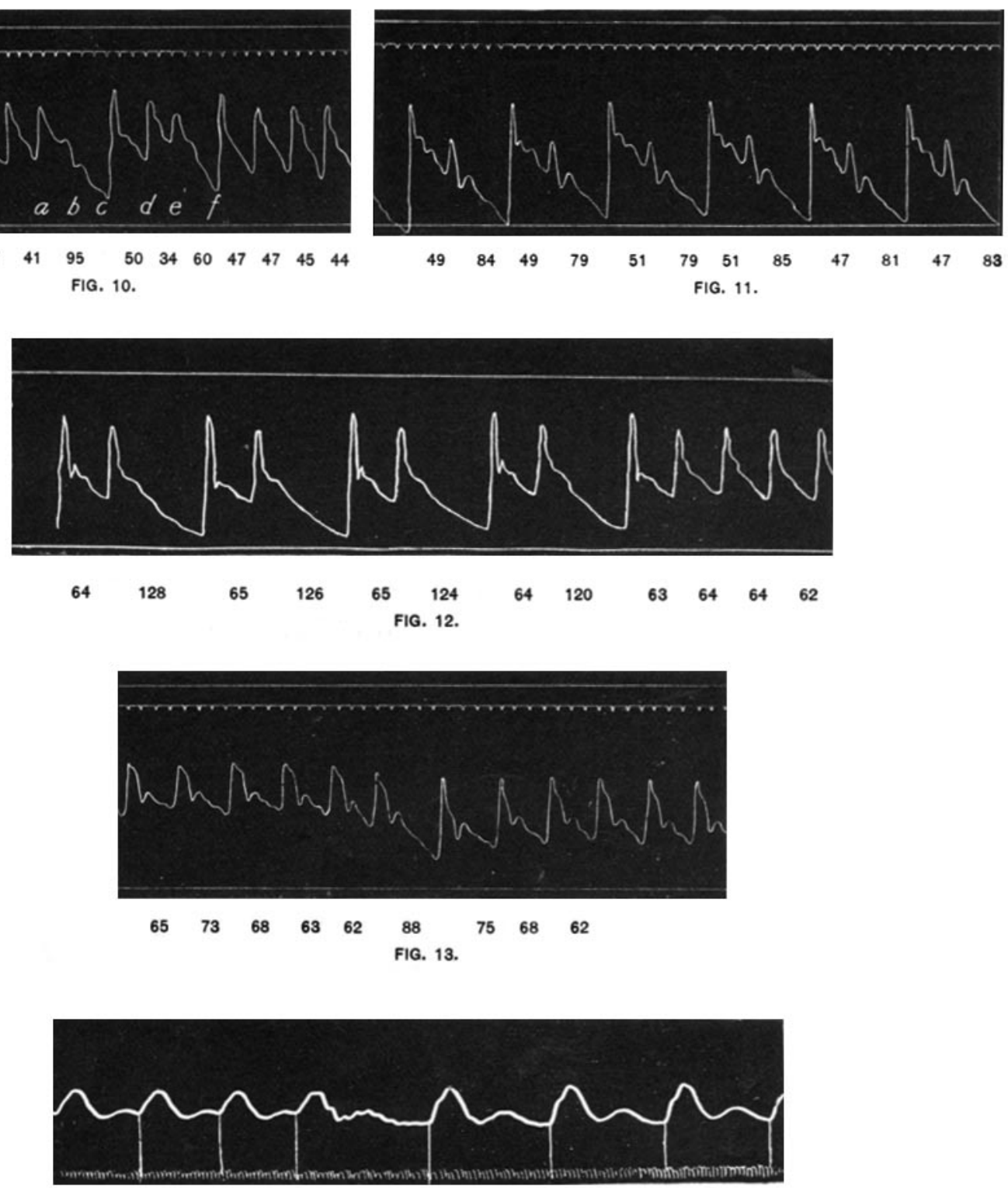

39

38

64

56

54

48

FIG. 14. 
TABLE I.

Duration of Intermissions in the Dog's Pulse under Stimulation of the Ventricle and Auricle (see page 332 ).

A.

Normal Pulseinterval.

Expt. 1. 54

55

54

54

53

52

54

53

55

55

54

54

Expt. 2. 40

39

40

39

38

39

38

38

38

38
B.

Chamber Stimulated.

C.

Intermission

Ventricle.

"

6

Auricle.

"

6

،

“

،

“

Ventricle.

6

Auricle.

$a$

"

"6

“

"

98

92

100

100

98

88

93

98

91

$[27+42] 69$

62

65

67

62

$\left.\begin{array}{ccc}107 & 1 & \frac{1}{54} \\ 110 & 0 & 0 \\ 108 & 0 & 0\end{array}\right)$

$10 \quad \frac{10}{54}$

$14 \quad \frac{14}{53}$

4

8

8

$\frac{\overline{53}}{8} \quad \overline{9}(\overline{13}-\overline{5})$

22

17

10

$10 \quad \frac{10}{54}$

$17 \quad \frac{17}{54}$

$\left.\begin{array}{ll}1 & \frac{1}{40} \\ 0 & 0 \\ 0 & 0\end{array}\right\}$

16

12

9
E. Average of

E. 
TABLE II.

Intermissions which approximated the type observed in the Dog on Stimulation of the Ventricle (see page 334 ).

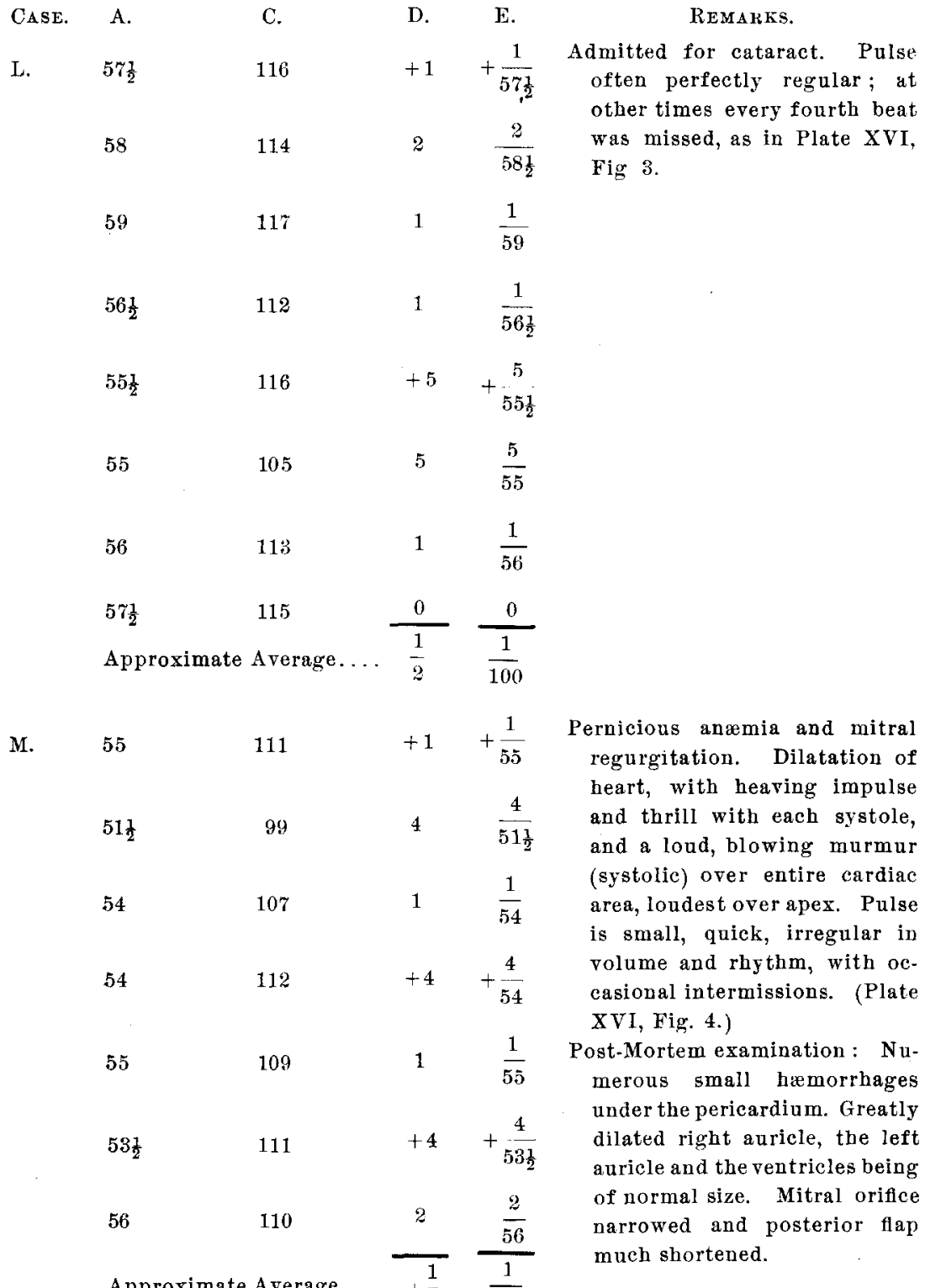




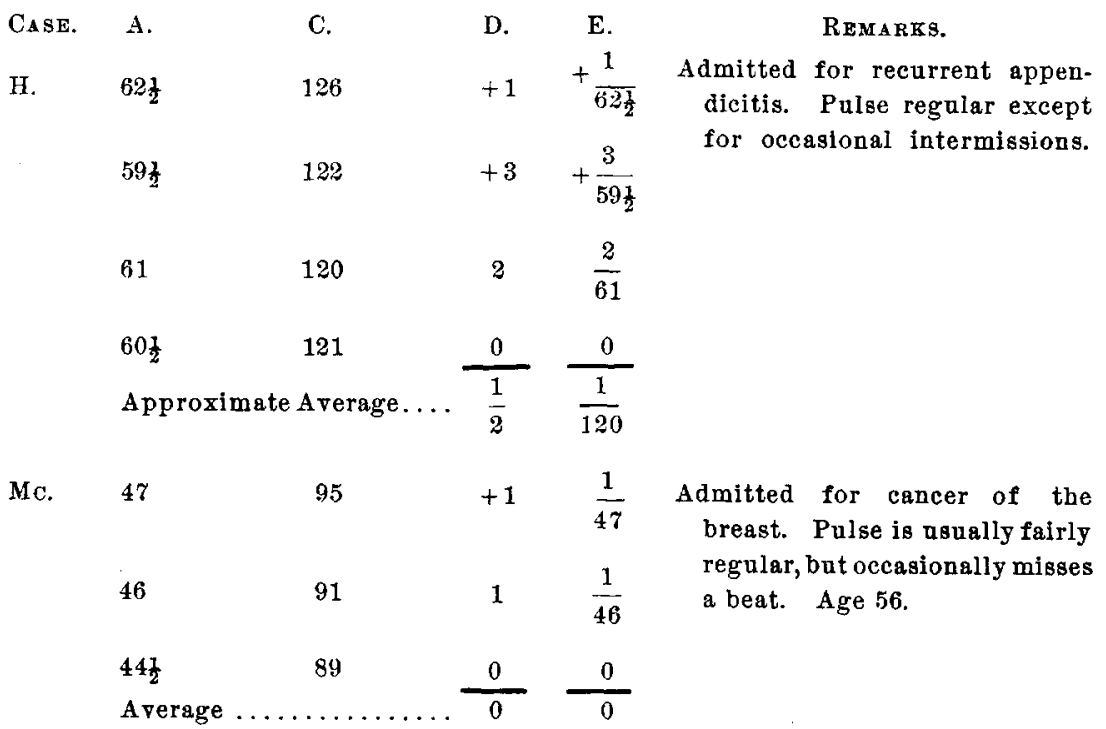

W. $\quad 64 \frac{1}{2} \quad 128 \quad 1 \quad \frac{1}{64} \quad \begin{array}{lll}\text { Age 22. Admitted for hernia. }\end{array}$

64 Heart ordinarily regular, but

often misses every third beat

$65 \quad 426 \quad \frac{4}{65} \quad$ for several minutes at a time.

$64 \frac{1}{2} \quad 124 \quad 5 \quad \frac{5}{6+\frac{3}{2}}$

$\begin{array}{cccc}65 & 126 & 4 & \frac{4}{65} \\ 60 & 120 & 0 & \frac{0}{1} \\ & \text { Approximate Average.... } & 3 & \end{array}$

Ma. 7

$\begin{array}{lcccc}77 & 154 & 0 & 0 \\ 76 \frac{1}{2} & 152 & 1 & \frac{1}{76} \\ 80 & 157 & 3 & \frac{3}{80} \\ & & & \frac{1}{60}\end{array}$

Age 59. Admitted for retention of urine. Occasionally the pulse misses a beat, but it is generally quite regular.

\begin{tabular}{|c|c|c|}
\hline 59 & $(46+73) 119$ & +1 \\
\hline 58 & $(45+70) 115$ & 1 \\
\hline 60 & $(46+74) 120$ & 0 \\
\hline
\end{tabular}

Medical student, complains of heart missing every second beat for several minates, and then becoming regular. (Plate XVII, Fig. 11.) 
TABLE III.

Intermissions which approximated those observed in the Dog on stimulation of the Auricle (see page 334 ).

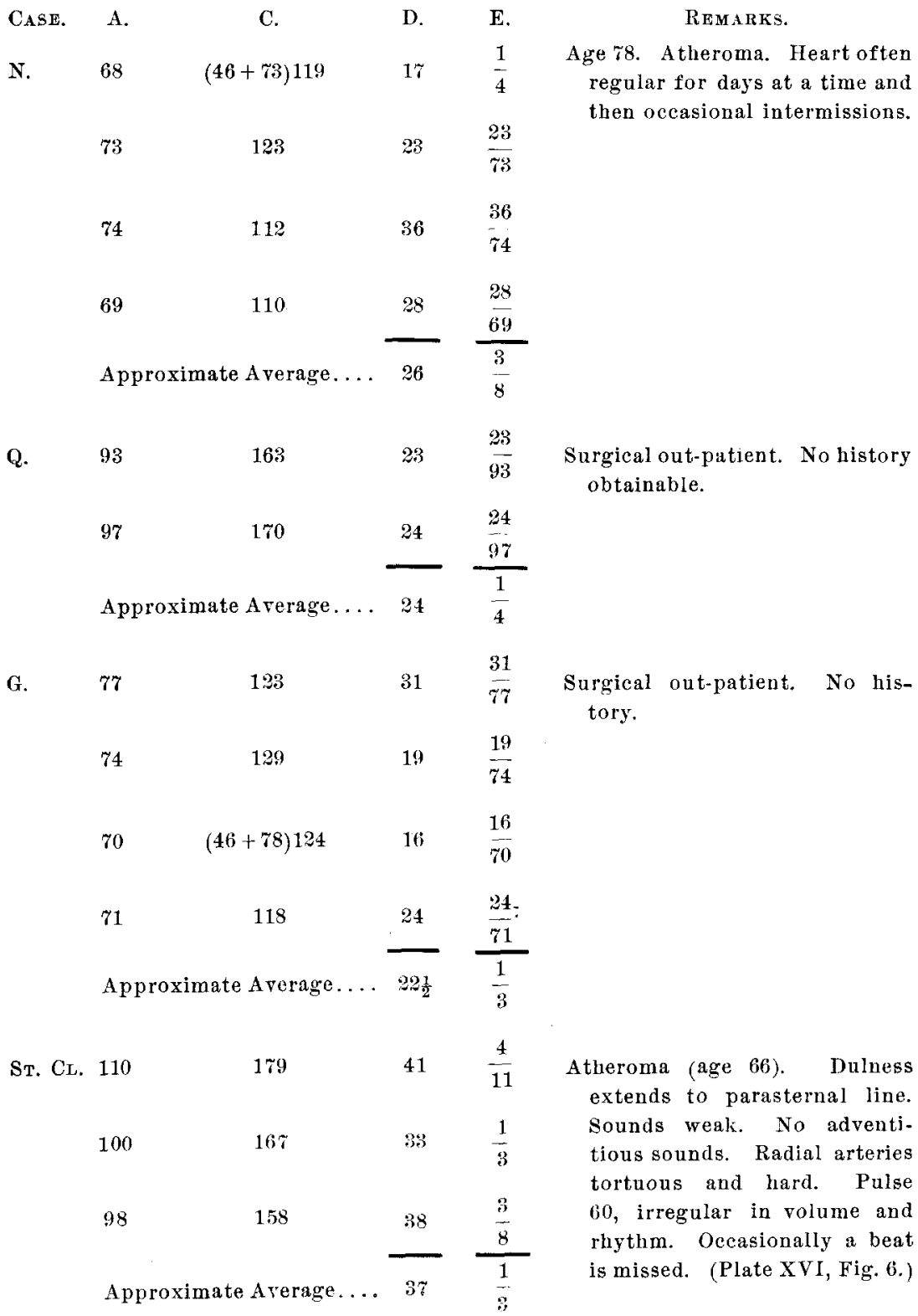


TABLE III.-Continued.

\begin{tabular}{|c|c|c|c|c|c|}
\hline CASE. $_{\text {A }}$ & A. & C. & D. & E. & Remarks. \\
\hline \multirow[t]{8}{*}{ SH. } & 65 & 122 & 8 & $\frac{1}{8}$ & \multirow{8}{*}{$\begin{array}{l}\text { Blacksmith. Dilation and hyper- } \\
\text { trophy of the heart, double } \\
\text { aortic lesions, mitral regurgi- } \\
\text { tation and tricuspid regurgi- } \\
\text { tation. General anasarca. } \\
\text { Pulse often misses a beat. } \\
\text { Post-Mortem examination: Great } \\
\text { distension of all the chambers, } \\
\text { and distinct separation of the } \\
\text { muscle fibres in the auricle. }\end{array}$} \\
\hline & 72 & 134 & 10 & $\frac{1}{7}$ & \\
\hline & 69 & 115 & 23 & $\underline{1}$ & \\
\hline & & & & 3 & \\
\hline & 71 & 127 & 15 & $\frac{15}{71}$ & \\
\hline & 66 & 114 & 18 & $\underline{18}$ & \\
\hline & & & & 66 & \\
\hline & $\mathrm{Apr}$ & nate Average... & 15 & $\frac{2}{0}$ & \\
\hline \multirow[t]{16}{*}{ K. } & 69 & 118 & 20 & $\underline{2}$ & \multirow{16}{*}{$\begin{array}{l}\text { Age 77. Surgical case. Pulse } \\
\text { often misses a beat, and in the } \\
\text { intermission a premature pul- } \\
\text { sation is sometimes present } \\
\text { (Plate XVI, Fig. 8). Some- } \\
\text { times the intermission occurs } \\
\text { alone in a series of regular } \\
\text { beats. In other tracings a } \\
\text { number of consecutive inter- } \\
\text { missions occur. }\end{array}$} \\
\hline & & & & 7 & \\
\hline & 58 & 100 & 16 & $\frac{16}{58}$ & \\
\hline & 57 & 100 & 14 & $\frac{14}{57}$ & \\
\hline & 65 & 110 & 20 & $\underline{20}$ & \\
\hline & & & & 65 & \\
\hline & 63 & 104 & 22 & $\underline{1}$ & \\
\hline & & & & 3 & \\
\hline & 62 & 105 & 19 & $\underline{19}$ & \\
\hline & & & & 62 & \\
\hline & 64 & $110(40+70)$ & 18 & $\underline{1}$ & \\
\hline & & & & 4 & \\
\hline & 69 & 114 & 24 & $\underline{1}$ & \\
\hline & & & & 3 & \\
\hline & Apl & nate Average.... & 19 & 5 & \\
\hline & & & & 16 & \\
\hline \multirow[t]{10}{*}{ D. } & 81 & 147 & 15 & $\frac{15}{81}$ & \multirow{10}{*}{$\begin{array}{l}\text { Acute rheumatism. Dilatation } \\
\text { of the heart towards left. } \\
\text { First sound is short and accom- } \\
\text { panied by a soft blowing mur- } \\
\text { mur. Over the pulmonary area } \\
\text { is heard a soft blowing mur- } \\
\text { mur with the first sound. } \\
\text { Radial pulse moderately } \\
\text { strong, 75, quick, at times } \\
\text { every third beat is dropped } \\
\text { (Plate XVII, Fig 9), and then } \\
\text { again the heart becomes more } \\
\text { regular or the intermissions } \\
\text { appear at longer intervals. } \\
\text { Heart improved under salicylic } \\
\text { acid treatment. }\end{array}$} \\
\hline & 811 & 145 & & 18 & \\
\hline & -2 & 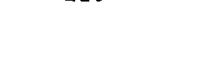 & 10 & $\overline{81}$ & \\
\hline & 83 & 148 & 16 & 16 & \\
\hline & & & & 83 & \\
\hline & 83 & 147 & 19 & $\frac{19}{83}$ & \\
\hline & & & & 13 & \\
\hline & \multirow{3}{*}{\multicolumn{2}{|c|}{ Approximate Average... }} & 13 & 83 & \\
\hline & & & & 1 & \\
\hline & & & 10 & & \\
\hline
\end{tabular}

